\title{
Influência do Plano Nutricional sobre o Desempenho de Bezerros Holandeses para Produção de Vitelos ${ }^{1}$
}

\author{
Telma Regina Ribeiro², José Carlos Pereira ${ }^{3}$, Marcus Vinícius Morais de Oliveira4, \\ Augusto César de Queiroz ${ }^{3}$, Paulo Roberto Cecon ${ }^{5}$, Maria Ignez Leão ${ }^{3}$, Rosana Coelho de Alvarenga e Melo 4
}

RESUMO - O experimento foi realizado com 20 bezerros holandeses, todos machos não castrados, com 75 dias de idade e peso vivo médio de $76 \mathrm{~kg}$, com o objetivo de avaliar o desempenho e a viabilidade econômica de produzir vitelos. Os animais foram alimentados com dietas contendo $45,60,75$ e $90 \%$ de concentrado. As dietas foram constituídas de feno de capim-coastcross, fubá de milho, farelo de soja e mistura mineral. O delineamento experimental foi em blocos casualizados, com quatro tratamentos e cinco blocos. Antes do início do experimento, todos os animais foram submetidos a um mesmo sistema de aleitamento. O período experimental foi variável para cada tratamento, em que os animais eram abatidos à medida que atingiam o peso médio de $200 \mathrm{~kg}$. As análises de variância para consumo de matéria seca, consumo de proteína bruta e conversão alimentar da matéria seca mostraram não haver efeito significativo dos níveis de concentrado nas dietas. Todavia, as análises de regressão mostraram efeito linear decrescente, com o aumento do nível de concentrado, para o consumo de fibra em detergente neutro, e aumento linear para o ganho de peso diário, proporcionando redução de 35 dias no confinamento para os animais alimentados com dietas contendo $90 \%$ de concentrado. Efeitos significativos devido ao nível de concentrado também foram verificados na conversão alimentar da fibra detergente neutro e da proteína bruta, sendo que a melhora da eficiência alimentar ocorreu com o acréscimo de concentrado na dieta. Os custos de produção indicaram a viabilidade de produzir vitelos utilizando bezerros holandeses.

Palavras-chave: bezerros holandeses, custo de produção, desempenho, níveis de concentrado, vitelos

\section{Influence of Nutritional Plane on Performance of Holstein Veal Calves}

ABSTRACT - The experiment was carried out with 20 intact Holsteins male calves, average live weight of $75 \mathrm{~kg}$ and 76 days old, to evaluate the performance and the economical viability to produce veal calves. The calves were fed diets containing $45,60,75$ and $90 \%$ of concentrate. Diets were composed of coastcross hay, ground corn, soybean meal and mineral mixture, fed ad libitum. The experimental design was a complete randomized blocks, with four treatments and five replicates. Before the beginning of the experiment, all the animals were submitted to the same nursing system. The experimental period was different for each treatment, since the animals were slaughtered as they reached an average weight of $200 \mathrm{~kg}$. The variance analyses for dry matter and crude protein intake and dry matter conversion showed no significant effect of the concentrate levels in the diets. However, the regression analyses showed a decreasing linear effect as the concentrate level for the neutral detergent fiber intake increased, and a linear increase in the average daily gain, reducing in 35 days of feedlot for the animals fed $90 \%$ of concentrate. Significant effects due to the concentrate level were also observed for neutral detergent fiber and crude protein feed:gain ratio, and the improvement of the feed efficiency occurred as the concentrate level in the diet increased. The production costs analysis showed the viability to produce veal calves from Holstein bull calves.

Key Words: Holstein calves, levels of concentrate, performance, production cost, veal calves

\section{Introdução}

A busca pela melhoria da eficiência da produção de carne tem mudado o perfil da pecuária, pois, dependendo de diversos fatores, tem alcançado posições diferentes no que diz respeito a uma intensificação total (EUCLIDES FILHO et al., 1996).

Anualmente, nas principais bacias leiteiras do
Brasil, milhares de bezerros machos são sacrificados ao nascer, eliminando-se assim uma fonte de renda em potencial. Os machos de raças mais apuradas são sacrificados logo após o nascimento, pois, apesar de seu maior potencial para ganhar peso, não conseguem se adaptar às condições rústicas de um sistema de criação mais extensivo (ALLEONI et al., 1980; LUCCI, 1989).

\footnotetext{
${ }_{1}$ Parte da tese apresentada à UFV, pelo segundo autor, para obtenção do título de Mestre em Zootecnia, financiada pelo CNPq

2 Eng $^{\circ}$-Agr ${ }^{\circ}$, MS em Zootecnia.

${ }^{3}$ Professores do DZO/Universidade Federal de Viçosa, Bolsistas do CNPq.

4 Zootecnista, Estudantes de Doutorado do DZO/UFV e DEA/UFV. E.mail: ds16672@correio.ufv.br; zana@dea.ufv.br

5 Professor do DPI/UFV.
} 
$\mathrm{Na}$ realidade, o que ocorre é que a maioria dos produtores depende quase que exclusivamente da receita garantida com a venda do leite. O bezerro, durante a fase de aleitamento, requer quantidade de leite que, se não for vendida, diminuirá a receita do produtor (BIONDI et al., 1984).

Todavia, se o custo desta fase puder ser diminuído com o uso restrito de leite, ou com a utilização de sucedâneos, o menor desempenho destes animais, desde que o crescimento não seja prejudicado de forma irreversível, poderá ser compensado posteriormente com o uso de dietas equilibradas. Desse modo, estes animais poderiam proporcionar boa fonte de renda, principalmente se forem vendidos a um mercado consumidor diferenciado, localizado basicamente nos grandes centros urbanos, onde podem ser pagos preços mais elevados por uma carne nobre e de melhor qualidade.

Em diversos países de pecuária evoluída, este segmento de mercado é bastante explorado, com os bezerros provenientes de rebanhos da raça Holandesa destinados à produção de vitelos (BOER, 1991; GROENEVELT, 1991; BUHR, 1996).

Os sistemas de produção de vitelos foram desenvolvidos principalmente na Europa, devido à demanda de carnes especiais e à disponibilidade de subprodutos lácteos, como leite em pó desengordurado e soro de leite (PEREIRA e OLIVEIRA, 2000).

USDA (1995) define o vitelo como o bovino imaturo destinado à produção de carne e apresenta uma classificação constituída por quatro grupos; animais abatidos compeso vivo variando dos 70 aos $250 \mathrm{~kg}$.

$\mathrm{Na}$ Europa, os sistemas normalmente utilizados incluem o animal de "carne branca", "carne vermelha" e "bezerros em engorda intensiva", com os pesos de abate variando de 100 a $450 \mathrm{~kg}$ e idade entre 3 e 12 meses (PEREZ REDONDO, 1990). Na sistemática americana, uma das classes, o "vitelo não especial", recebe como alimentos o sucedâneo de leite, volumosos diversos e concentrados, podendo ser abatido com peso de até $200 \mathrm{~kg}$. O correspondente no sistema europeu, o "vitelo de carne vermelha", é abatido aos 5-6 meses de idade, com 225 a $250 \mathrm{~kg}$ de peso vivo.

No Brasil, existe demanda de carne bovina de qualidade, de forma que os produtores de leite cujas propriedades estão localizadas nas proximidades de grandes centros consumidores poderiam se estruturar para estabelecer sistemas de produção desta natureza. Entretanto, deve-se atentar que, nestes sistemas, são desejados altos ganhos de peso em menor tempo possível e, dessa forma, torna-se necessária a administração de dietas balanceadas e com alta porcentagem de concentrados.

Em decorrência destas considerações, objetivou-se no presente trabalho avaliar o desempenho e o custo de produção de bezerros holandeses puros por cruza, alimentados com dietas contendo diferentes níveis de concentrado, para produção de vitelos.

\section{Material e Métodos}

Foram utilizados 20 bezerros holandeses puros por cruza (HPC), machos não-castrados, com idade aproximada de 75 dias e peso médio de $76 \mathrm{~kg}$. Os animais foram mantidos em regime de confinamento, em baias individuais, com piso concretado de $8 \mathrm{~m}^{2}$, sendo a área coberta com telha de amianto, providas de comedouro e bebedouro de concreto.

Do nascimento até o início do experimento, os animais foram submetidos a um único sistema de aleitamento, que consistiu de quatro litros de uma mistura preparada com um sucedâneo comercial do leite, fornecidos duas vezes ao dia, durante 60 dias. Todos os animais durante esse período tiveram acesso a volumoso - feno de capim-coastcross (Cynodon dactylon (L.) Pers.) picado - e ração concentrada à vontade.

Os 20 animais foram sorteados aleatoriamente, em cinco blocos com quatro animais cada, distribuídos ao acaso entre quatro tratamentos, que compreenderam quatro níveis de concentrado na dieta.

$\mathrm{O}$ período de adaptação às instalações e ao sistema de manejo empregado teve duração de 15 dias, durante o qual todos os animais receberam a ração utilizada no período experimental à vontade.

Antes do período experimental, todos os animais, além de receberem vitamina A injetável, foram tratados contra endo e ectoparasitas, pesados e identificados com brincos numerados na orelha direita.

O período experimental foi variável para cada tratamento; por conseguinte, não teve duração préfixada, posto que os animais eram abatidos à medida que atingiam o peso médio de $200 \mathrm{~kg}$, em função do sistema de produção preconizado.

As dietas foram constituídas de feno triturado de capim-coastcross como volumoso, farelo de soja, fubá de milho, calcário e mistura mineral, sendo calculadas com base nas exigências nutricionais estabelecidas pelo NRC (1988), para um ganho de peso esperado de $1,0 \mathrm{~kg}$ diário para essa categoria animal.

Rev. bras. zootec., 30(6S):2145-2153, 2001 
Foram preparadas quatro rações experimentais, cujas composições são apresentadas na Tabela 1 . Os resultados da análise bromatológica dos ingredientes e a composição percentual dos nutrientes das dietas são apresentados nas Tabelas 2 e 3.

Durante toda a fase experimental, o alimento foi fornecido à vontade uma vez ao dia, às 7 h30. Procurou-se, sempre, manter as sobras em torno de $10 \%$ do peso total do alimento oferecido, mas, quando necessário, a quantidade de alimento fornecido era ajustada. Para determinação do consumo alimentar, foram anotadas, diariamente, as quantidades de ração fornecidas e rejeitadas.

Diariamente, coletaram-se amostras de sobras de cada baia, que foram reunidas em amostras compostas semanais. Estas amostras foram agrupadas em amostras compostas para cada período de quatro semanas, para posteriores análises químicas.

As análises bromatológicas foram realizadas no Laboratório de Nutrição Animal do Departamento de Zootecnia da Universidade Federal de Viçosa - MG. As análises de matéria seca (MS), proteína bruta

Tabela 1 - Composição percentual dos ingredientes das rações (base da matéria seca)

Table 1 - Percentage composition of ingredients of the diets (dry matter basis)

\begin{tabular}{|c|c|c|c|c|}
\hline \multirow[t]{2}{*}{$\begin{array}{l}\text { Ingredientes } \\
\text { Ingredients }\end{array}$} & \multicolumn{4}{|c|}{$\begin{array}{l}\text { Rações } \\
\text { Diets }\end{array}$} \\
\hline & 45 & 60 & 75 & 90 \\
\hline $\begin{array}{l}\text { Feno coastcross } \\
\text { Coastcross hay }\end{array}$ & 54,10 & 38,80 & 23,49 & 8,20 \\
\hline $\begin{array}{l}\text { Fubá de milho } \\
\text { Ground corn grain }\end{array}$ & 24,44 & 41,20 & 57,97 & 74,49 \\
\hline $\begin{array}{l}\text { Farelo de soja } \\
\text { Soybean meal }\end{array}$ & 20,56 & 18,80 & 17,04 & 15,51 \\
\hline $\begin{array}{l}\text { Mistura mineral }^{1} \\
\text { Mineral mixture }^{1}\end{array}$ & 0,45 & 0,60 & 0,75 & 0,90 \\
\hline $\begin{array}{l}\text { Calcário } \\
\text { Limestone }\end{array}$ & 0,45 & 0,60 & 0,75 & 0,90 \\
\hline
\end{tabular}

${ }^{1}$ Mistura mineral contendo em cada kg: $420 \mathrm{~g}$ de fosfato bicálcico, $54 \mathrm{~g}$ de calcário calcítico; $519,12 \mathrm{~g}$ de cloreto de sódio; $2,0 \mathrm{~g}$ de sulfato de cobre; $4 \mathrm{~g}$ de óxido de zinco; $0,3 \mathrm{~g}$ de iodato de cálcio; $0,5 \mathrm{~g}$ de sulfato de cobalto e $0,8 \mathrm{~g}$ selenito de sódio.

${ }^{1}$ Mineral mix contents per $\mathrm{kg}: 420 \mathrm{~g}$ of dicalcium phosphate; $54 \mathrm{~g}$ of limestone; $519.12 \mathrm{~g}$ of sodium chloride; $2.0 \mathrm{~g}$ of cupper sulphate; $4.0 \mathrm{~g}$ of zinc oxide; $0.3 \mathrm{~g}$ of calcium iodate; $0.5 \mathrm{~g}$ of cobalt sulphate and $0.8 \mathrm{~g}$ of sodium selenite.
(PB) e fibra em detergente neutro (FDN) feitas nas amostras das rações foram conduzidas segundo metodologia descrita por SILVA (1990).

Para as análises das variáveis referentes ao desempenho dos animais, utilizou-se o delineamento em blocos casualizados com quatro tratamentos e cinco repetições, no qual cada animal representava uma unidade experimental.

Os dados foram interpretados por meio de análises de variância e regressão, utilizando-se o programa SAEG (Sistema de Análises Estatísticas e Genéticas), conforme UNIVERSIDADE FEDERAL DE VIÇOSA - UFV (1995). Os modelos foram escolhidos com base na significância dos coeficientes de regressão, pelo teste "t" de Student, a 5\%, conforme o coeficiente de determinação.

O modelo matemático utilizado foi:

$$
\mathrm{Y}_{\mathrm{ijk}}=\mu+\mathrm{b}_{\mathrm{j}}+\mathrm{t}_{\mathrm{i}}+\mathrm{e}_{\mathrm{ijk}} \text {, }
$$

em que: $\mathrm{Y}$ ijk = variável em questão, no tratamento i, no bloco $\mathrm{j}$, no período $\mathrm{k} ; \mu=$ média geral; $\mathrm{b}_{\mathrm{j}}=$ efeito do bloco $\mathrm{j}$, sendo $\mathrm{j}=1,2, . ., 5 ; \mathrm{t}_{\mathrm{i}}=$ efeito do tratamento $\mathrm{i}$, sendo $\mathrm{i}=$ níveis de concentrado nas dietas $(45,60$, $75,90)$; e eijk = erro aleatório.

Tabela 2 - Teores de matéria seca (MS), proteína bruta (PB) e fibra em detergente neutro (FDN) das rações experimentais

Table 2 - Drymatter(DM), crude protein (CP) and neutral detergent fiber (NDF) contents in the experimental diets

\begin{tabular}{lcccc}
\hline Nutrientes & \multicolumn{4}{c}{$\begin{array}{c}\text { Rações } \\
\text { Dutrients }\end{array}$} \\
\cline { 2 - 5 } & 45 & 60 & 75 & 90 \\
\hline MS $(D M)$ & 86,99 & 86,60 & 86,21 & 85,83 \\
PB $(C P)$ & 16,39 & 15,99 & 15,57 & 15,26 \\
FDN $(N D F)$ & 51,04 & 40,05 & 29,05 & 18,08 \\
\hline
\end{tabular}

Tabela 3 - Teores de matéria seca (MS), proteína bruta (PB) e fibra em detergente neutro (FDN) dos ingredientes das rações experimentais

Table 3 - Drymatter(DM), crude protein (CP) and neutral detergent fiber (NDF) contents of the ingredients of the experimental diets

\begin{tabular}{lccc}
\hline $\begin{array}{l}\text { Ingredientes } \\
\text { Ingredients }\end{array}$ & $\begin{array}{c}\mathrm{MS}(\%) \\
D M(\%)\end{array}$ & $\begin{array}{c}\mathrm{PB}(\% \mathrm{MS}) \\
C P(\% D M)\end{array}$ & $\begin{array}{c}\mathrm{FDN}(\% \mathrm{MS}) \\
\text { NDF }(\% D M)\end{array}$ \\
\hline $\begin{array}{l}\text { Feno de coastcross } \\
\begin{array}{l}\text { Coastcross hay } \\
\text { Fubá de milho }\end{array}\end{array}$ & 88,22 & 6,77 & 83,40 \\
$\begin{array}{l}\text { Ground corn grain } \\
\text { Farelo de soja } \\
\text { Soybean meal }\end{array}$ & 87,38 & 9,10 & 12,10 \\
\hline
\end{tabular}


Na apreciação econômica dos resultados obtidos, considerou-se, como despesas, o valor dos bezerros desaleitados, ao início do experimento, bem como os gastos relativos a fatores de produção exclusivamente usados no experimento. Logo, não foram considerados, como despesas, os fluxos de serviços e benfeitoria, máquinas empregadas, assim como transporte dos animais e depreciação em geral.

Com relação aos gastos com mão-de-obra e medicamentos, utilizaram-se estritamente aqueles que ocorreram em cada tratamento.

Utilizaram-se preços de mercado de Viçosa - Minas Gerais, em outubro de 1996, e o custo de produção dos bezerros até o desaleitamento foi tomado com base em trabalhos realizados na Universidade Federal de Viçosa e dados da EMBRAPA - Gado de Leite.

\section{Resultados e Discussão}

A análise de variância para consumo de matéria seca, expressa em kg/dia (CMS), em porcentagem de peso vivo (CMSPV) e em função do peso metabólico (CMSPM), mostrou não haver efeito significativo ( $\mathrm{P}>0,05)$ dos níveis de concentrado nas dietas estudadas. $\mathrm{Na}$ Tabela 4, são apresentadas as médias de consumo das variáveis citadas acima, que permaneceram constantes para os níveis de concentrado nas dietas e próximas ao valor estipulado pelo NRC (1988).

Parrott et al. (1968) e Meiske e Goodrich (1972), citados por HIRONAKA et al. (1994), afirmaram que a ingestão alimentar de matéria seca pode ser menor em dietas constituídas exclusivamente de concentrados que aquelas com 5 a $20 \%$ de forragem.

Tabela 4 - Consumo médio de matéria seca (CMS) em bezerros holandeses recebendo dietas com diferentes níveis de concentrado

Table 4 - Average dry matter intake (DMI) in Holstein bull calves fed diets with different concentrate levels

\begin{tabular}{lccccc}
\hline \multicolumn{5}{c}{$\begin{array}{l}\text { Níveis de concentrado nas dietas (\% MS) } \\
\text { Levels of concentrate in the diets (\% DM) }\end{array}$} \\
\cline { 2 - 6 } $\begin{array}{l}\text { Unidades de } \\
\text { consumo }\end{array}$ & 45 & 60 & 75 & 90 & $\begin{array}{c}\text { Média } \\
\text { Mean }\end{array}$ \\
$\begin{array}{l}\text { Intake units } \\
\text { kg/dia }\end{array}$ & 3,88 & 4,04 & 3,88 & 4,09 & 3,97 \\
$\begin{array}{l}\mathrm{kg} / \text { day } \\
\text { \% peso vivo }\end{array}$ & 2,72 & 2,71 & 2,63 & 2,54 & 2,65 \\
$\begin{array}{l}\text { \% live weight } \\
\text { g/kg peso } \\
\text { metabólico } \\
\text { g/kg metabolic weight }\end{array}$ & 94,73 & 94,75 & 91,38 & 87,99 & 92,21 \\
\hline
\end{tabular}

Rev. bras. zootec., 30(6S):2145-2153, 2001
Segundo esses autores, isso é devido ao aumento do consumo de energia digestível, quando as mesmas são fornecidas à vontade, o que está de acordo com os resultados obtidos.

Também é conclusivo que, quando o consumo diário de energia e o ganho são praticamente constantes, ocorre queda no consumo de matéria seca, em virtude do aumento da densidade energética.

O consumo por unidade de peso metabólico pode ser alto no período inicial da alimentação, mas, posteriormente, ocorre rápida diminuição (FOX e BLACK, 1984). O conhecimento dos mecanismos controladores do consumo indicam que este não é simplesmente um atributo do alimento, mas da interação de uma série de fatores; assim, apesar da variabilidade existente entre as dietas, no que se refere ao teor de fibra, não houve efeito sobre o consumo de matéria seca.

As análises de variância para consumo de FDN em $\mathrm{kg} / \mathrm{dia}(\mathrm{CFDN})$, expresso em porcentagem de peso vivo (CFDNPV) e em função do peso metabólico (CFDNPM), mostraram haver efeito significativo $(\mathrm{P}<0,05)$ para os níveis de concentrado nas dietas.

As análises de regressão mostraram efeito linear decrescente $(\mathrm{P}<0,01)$, para CFDN, CFDNPV e CFDNPM, com a elevação dos níveis de concentrado nas dietas. As equações de regressão e seus respectivos coeficientes de determinação podem ser observadas nas Figuras 1 e 2.

Para um perfeito balanço microbiano no rúmen, é importante a manutenção de quantidades mínimas de fibra na ração; nesse sentido, o NRC (1988) indica valor de $23 \%$ de FDN, para bezerros na faixa de 3 a 6 meses.

Estes resultados são lógicos, já que existe uma

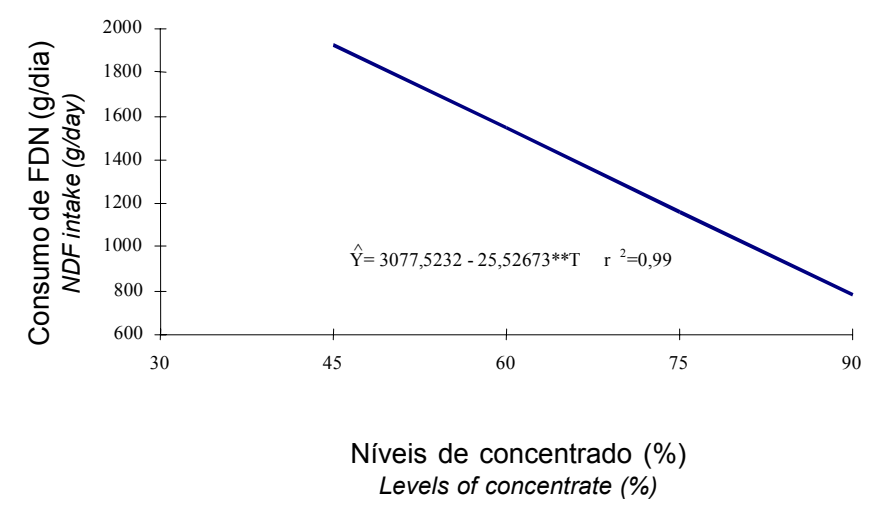

Figura 1 - Estimativa do consumo diário de FDN (g/dia), em função dos níveis de concentrado nas dietas.

Figure 1 - Estimate of the daily NDF intake (g/day), in relation to the levels of concentrate in the diets. 


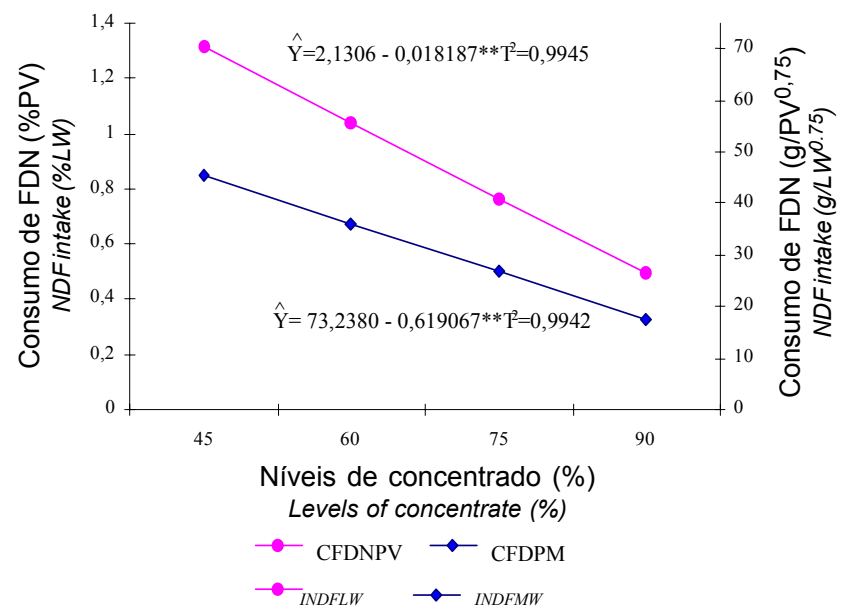

Figura 2 - Estimativa do consumo de FDN expresso em porcentagem de peso vivo (CFDNPV) e em unidade de peso metabólico (CFDPM), em função dos níveis de concentrado nas dietas.

Figure 2 - Estimate of the NDF intake in percentage of live weight (INDFLW) and metabolic weight units (INDFMW), in relation to the levels of concentrate in the diets.

relação inversa entre o teor de FDN na dieta e o nível de concentrado, refletindo assim o efeito do feno, já que o mesmo apresentou elevado teor de fibra. Estes resultados de consumo de FDN, associados ao CMS, indicam que a limitação de consumo que ocorreu em todos os tratamentos foi decorrente da saciedade energética, e não física, como poderia ser imaginado, devido à reduzida idade destes animais.

Mertens (1988), citado por RESENDE (1994), encontrou valor de $1,2 \%$ do peso vivo do animal para a ingestão de FDN da ração, chegando a valores de $1 \%$ para animais em fase de crescimento, os quais, ultrapassados, implicariam na restrição da ingestão pelo efeito do enchimento do rúmen-retículo. Também, MERTENS (1992) enfatizou que restrições no consumo, devido ao enchimento do rúmen-retículo pelo excesso de fibra, são verificadas em níveis de consumo de FDN superiores a $1,2 \% \mathrm{PV}$. No presente trabalho, as estimativas do consumo em função do peso vivo apresentaram valores entre 1,3 e $0,5 \%$, para os níveis de 45 e $90 \%$ de concentrado, respectivamente.

As análises de variância para consumo de proteína bruta, expresso em porcentagem de peso vivo (CPBPV) e em peso metabólico (CPBPM), mostraram não haver efeito significativo $(\mathrm{P}<0,05)$ para os níveis de concentrado nas dietas estudadas. As médias encontradas foram 0,$406 ; 0,412 ; 0,404 ; 0,378 \%$
(CPBPV) e 14,$15 ; 14,33 ; 13,97 ; 13,70 \mathrm{~g} / \mathrm{UPM}$ (CPBPM), para os níveis de 45, 60, 75 e 90\% de concentrado, respectivamente. O mesmo aconteceu para o consumo de proteína bruta, expresso em $\mathrm{g} / \mathrm{dia}$, em que as análises mostraram não haver efeito ( $\mathrm{P}>0,05)$ para os níveis de concentrado estudados. As médias encontradas foram 598,$82 ; 614,59 ; 593,85$; e $599,88 \mathrm{~g} /$ dia para os níveis de $45,60,75$ e $90 \%$ de concentrado, respectivamente.

Observa-se que, com a elevação dos níveis de concentrado nas dietas, o consumo de proteína bruta expresso em função do peso metabólico ou em porcentagem do peso vivo foi menor, o que pode estar relacionado ao consumo de matéria seca, pois, como foi citado anteriormente, os animais que receberam dietas contendo menores níveis de concentrado consumiram maiores quantidades de matéria seca que os alimentados com maiores porcentagens de concentrado em suas dietas.

As análises de variância dos dados de conversão alimentar para matéria seca (CAMS), proteína bruta (CAPB) e fibra em detergente neutro (CAFDN) mostraram haver efeito significativo $(\mathrm{P}<0,05)$ para os níveis de concentrado nas dietas.

As análises de regressão para a conversão alimentar da matéria seca (CAMS) mostraram não haver efeito $(\mathrm{P}>0,05)$ para os níveis de concentrado estudados. Os dados relativos às médias, em função dos níveis de 45, 60, 75 e 90\% de concentrado, foram de 4,$37 ; 3,71 ; 4,03$; e 3,57, respectivamente.

Embora tenha sido verificado efeito dos níveis de concentrado nas dietas, pode-se observar que, com a elevação dos níveis de concentrado, houve tendência de os animais utilizarem mais eficientemente os alimentos para seu desenvolvimento, quando comparados àqueles alimentados com menores níveis de concentrado.

Observou-se efeito linear decrescente para a conversão alimentar da proteína bruta $(\mathrm{P}<0,05)$ e fibra em detergente neutro $(\mathrm{P}<0,01)$, conforme pode ser observado na Figura 3.

Houve melhor utilização dos nutrientes da ração pelos animais, com a elevação dos níveis de concentrado, mostrando, dessa maneira, que aqueles animais alimentados com $90 \%$ de concentrado utilizaram mais eficientemente a proteína e a fibra presentes nas rações em relação àqueles alimentados com $45 \%$ de concentrado. Este resultado, que provavelmente ocorreu em conseqüência do menor consumo de MS, ainda pode estar relacionado ao maior teor de

Rev. bras. zootec., 30(6S):2145-2153, 2001 


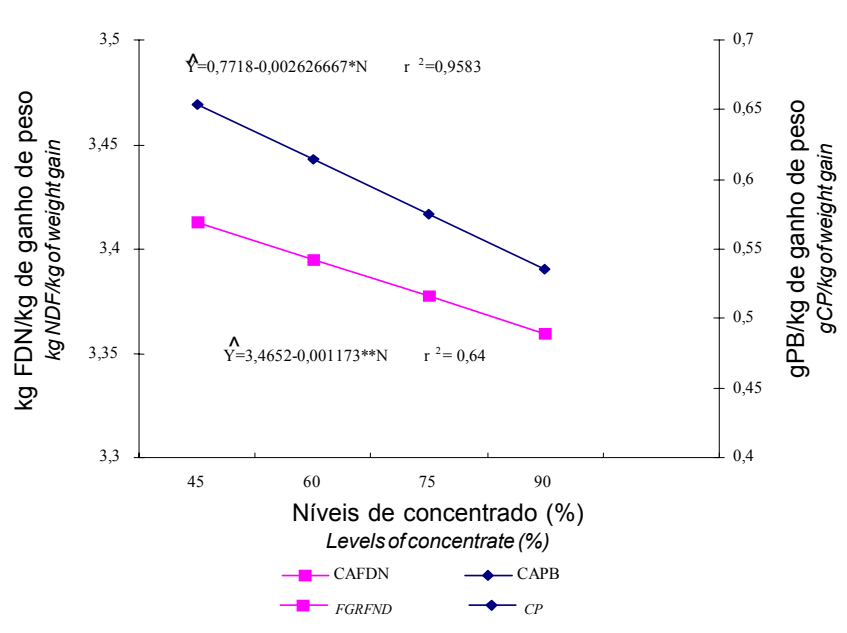

Figura 3 - Estimativa da conversão alimentar da fibra em detergente neutro (CAFDN) e da proteína bruta (CAPB), em função dos níveis de concentrado nas dietas.

Figure 3 - Estimate of the neutral detergent fiber (FGNDF) and crude protein (FGCP) feed:gain ratio, in relation to the levels of concentrate in the diets.

fibra (FDN) nas rações com menores níveis de concentrado, as quais, conseqüentemente, seriam menos digestíveis.

O ganho de peso vivo é uma medida indispensável para se estimar o desenvolvimento do animal nos sistemas de alimentação e produção (ROHR e DAENICKE, 1984).

As análises de regressão mostraram aumento linear $(\mathrm{P}<0,05)$ do ganho de peso médio diário(GPMD), com a elevação dos níveis de concentrado das dietas. A equação de regressão e seu respectivo coeficiente de determinação são apresentados na Figura 4.

Os resultados obtidos estão de acordo com HIRONAKA et al. (1994), com novilhos Hereford com peso inicial de $218 \mathrm{~kg}$, observando que o ganho de peso médio diário aumentou rapidamente com o acréscimo do nível de concentrado nas dietas, mas a taxa de ganho foi semelhante para os animais alimentados com níveis de concentrado acima de $65 \%$.

O ganho de peso é maior em animais alimentados com rações contendo maior percentagem de concentrado (PRESTON e WILLIS, 1974). De acordo com o trabalho conduzido por BOND et al. (1972), a velocidade de crescimento também foi conseqüência da alta quantidade de energia ingerida diariamente pelos animais que consumiram dietas constituídas basicamente de concentrado, quando comparados àqueles animais que consumiram dietas mistas (feno

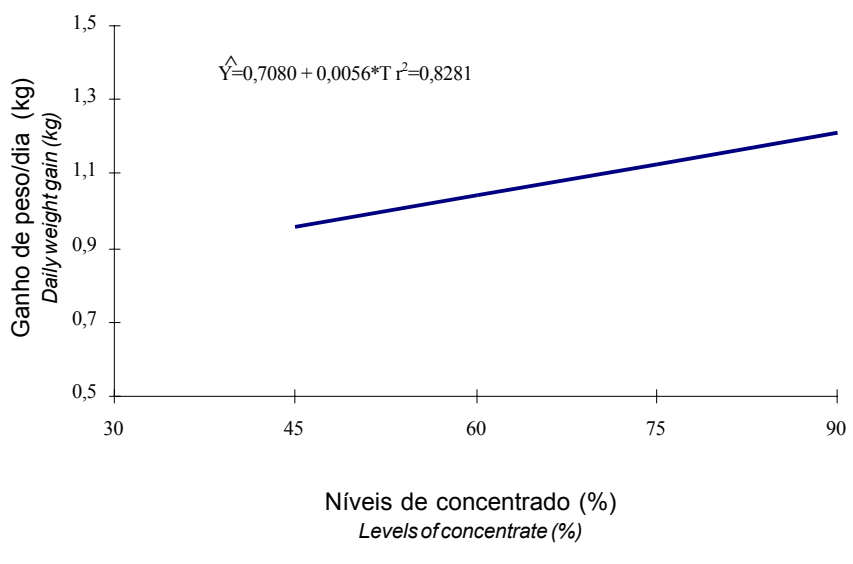

Figura 4 - Estimativa do ganho de peso médio diário (GPMD), em função dos níveis de concentrado nas dietas. Figure 4 - Estimate of average daily weight gain (AVG), in relation to the levels of concentrate in the diets.

+ concentrado) ou dietas com apenas feno. Nesse mesmo aspecto, GERRITS (1996), trabalhando com bezerros de 80 a $240 \mathrm{~kg}$ de peso vivo, verificou que o ganho de peso foi afetado pelo consumo de proteína bruta, sendo que as taxas de deposição de proteína e gordura aumentaram com o nível protéico.

A resposta animal à adição de concentrado é curvilínea e não-linear (HIRONAKA et al., 1994), entretanto, neste trabalho, foi linear com o aumento do nível de concentrado nas dietas. De acordo com PRESTON e WILLIS (1974), o nível ótimo de concentrado na ração é variável e tem, como fatores determinantes, sexo, raça e idade do animal, qualidade do volumoso e concentrado, entre outros.

Conforme FOX e BLACK (1984), deve-se considerar também que, em animais alimentados com dietas contendo mais de $90 \%$ de concentrado, o ganho diário poderá ser influenciado e, por conseguinte, ocorrerá rápida queda no consumo diário de matéria seca.

Conforme visto, os animais recebendo dietas com maiores níveis de concentrado apresentaram maiores taxas de ganho e, dessa forma, atingiram o peso de abate mais rapidamente, permanecendo assim menos tempo em confinamento. A relação entre dias de permanência em confinamento e níveis de concentrado na dieta foi significativa $(\mathrm{P}<0,05)$, conforme pode ser visto na Figura 5.

Para apreciação econômica dos resultados, anali-

Rev. bras. zootec., 30(6S):2145-2153, 2001 


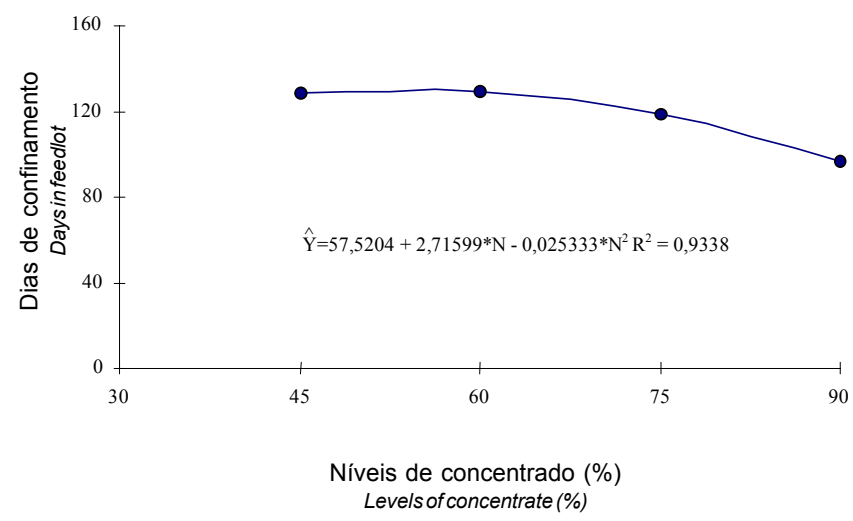

Figura 5 - Estimativa do tempo de permanência em confinamento, em função dos níveis de concentrado nas dietas.

Figure 5 - Estimate of feedlot days, in relation to the levels of concentrate in the diets. saram-se unicamente os custos; constam da Tabela 5 as quantidades e os preços da mão-de-obra e dos insumos utilizados, por animal, em cada dieta, e da Tabela 6, os dados gerais do sistema, além dos custos.

Observa-se que os custos totais foram bastante influenciados pelo gasto com a alimentação: o custo médio referente à alimentação dos bezerros no período de confinamento representou aproximadamente $91,0 \%$ dos custos totais. Também pode ser notado que maiores níveis de concentrado nas dietas proporcionaram melhores resultados, ao se avaliarem os valores obtidos para o custo/kg de ganho de peso obtido. O custo médio por arroba produzida, considerando-se as fases de aleitamento e confinamento, foi de $\mathrm{R} \$ 16,57$, o que permite deduzir o valor de venda adequado para que estes animais proporcionem rentabilidade satisfatória.

A produção de vitelos no Brasil ainda é restrita,

Tabela 5 - Preço unitário $(R \$)$ e quantidade de produto e insumos nas diversas dietas Table 5 - Unitary prices $(R \$)$ and quantity of product and inputs in the different diets

\begin{tabular}{|c|c|c|c|c|c|c|}
\hline \multirow[t]{2}{*}{ Itens } & \multirow[t]{2}{*}{$\begin{array}{l}\text { Unidade } \\
\text { Units }\end{array}$} & \multirow[t]{2}{*}{$\begin{array}{l}\text { Preço unitário- } \mathrm{R} \$ \\
\text { Unitary price } R \$\end{array}$} & \multicolumn{4}{|c|}{$\begin{array}{l}\text { Nível de concentrado nas dietas } \\
\text { Level of concentrate in the diets }\end{array}$} \\
\hline & & & 45 & 60 & 75 & 90 \\
\hline $\begin{array}{l}\text { 1. Valor bezerro desaleitado } \\
\text { Weaned calf value } \\
\text { 2. Despesas } \\
\text { Cost }\end{array}$ & & 78,00 & 78,00 & 78,00 & 78,00 & 78,00 \\
\hline $\begin{array}{l}\text { Mão-de-obra } \\
\text { Labor (hours/man) } \\
\text { Concentrado }\end{array}$ & Horas/homem & 5,51 & 1,89 & 1,82 & 1,80 & 1,39 \\
\hline $\begin{array}{l}\text { Concentrate } \\
\text { a. Farelo de soja } \\
\text { Soybean meal }\end{array}$ & $\mathrm{kg}$ & 0,34 & 131,61 & 116,73 & 103,82 & 82,07 \\
\hline $\begin{array}{l}\text { b. Fubá de milho } \\
\text { Ground corn grain }\end{array}$ & $\mathrm{kg}$ & 0,18 & 252,89 & 256,43 & 353,24 & 394,46 \\
\hline $\begin{array}{l}\text { c. Sal mineral } \\
\text { Mineral salt }\end{array}$ & $\mathrm{kg}$ & 0,26 & 6,69 & 6,45 & 6,24 & 5,41 \\
\hline $\begin{array}{l}\text { d. Calcário } \\
\text { Limestone } \\
\text { Volumoso }\end{array}$ & $\mathrm{kg}$ & 0,07 & 6,69 & 6,45 & 6,24 & 5,41 \\
\hline $\begin{array}{l}\text { Forage } \\
\text { a. Feno } \\
\text { Hay }\end{array}$ & $\mathrm{kg}$ & 0,18 & 252,89 & 257,12 & 154,99 & 53,99 \\
\hline $\begin{array}{l}\text { Vermífugo } \\
\text { Vermifuge }\end{array}$ & $\mathrm{ml}$ & 0,35 & 7,5 & 7,5 & 7,5 & 7,5 \\
\hline $\begin{array}{l}\text { Vitamina A.D.E. } \\
\text { Vitamin A.D.E. }\end{array}$ & $\mathrm{ml}$ & 0,06 & 7,5 & 7,5 & 7,5 & 7,5 \\
\hline
\end{tabular}


Tabela 6 - Dados gerais do desempenho e custos (R\$), nas dietas

Table 6 - Performance dates and costs $(R \$)$ in the diets

Nível de concentrado nas dietas

Level of concentrate in the diets

\begin{tabular}{lcccc}
\cline { 2 - 5 } Itens & \multicolumn{1}{c}{45} & 60 & 75 & 90 \\
\hline $\begin{array}{l}\text { Peso vivo médio final- kg } \\
\text { Final average live weight } \mathrm{kg}\end{array}$ & 195,70 & 200,90 & 195,50 & 196,6 \\
$\begin{array}{l}\text { Ganho peso diário- kg } \\
\text { Average daily gain-kg }\end{array}$ & 0,96 & 1,04 & 1,13 & 1,21 \\
$\begin{array}{l}\text { Duração do } \\
\text { nunyyyy }\end{array}$ & 130 & 125 & 123 & 95
\end{tabular}

confinamento-dias

Feedlot days

Despesas (R\$)

Costs (R\$)

Fase de aleitamento

Weaning phase

Fase de confinamento

Feedlot phase

Mão-de-obra

Labor

Alimentos

Feeds

Farelo de soja

Soybean meal

Fubá de milho

Ground corn grain

Salmineral

Mineral salt

Calcário

Limestone

Volumoso(feno)

Forage(hay)

Vermífugo

Vermifuge

Vitamina ADE

Vitamin A.D.E.

Total de despesas

Total of costs

Custo/kg ganho

no confinamento

Cost/kg gain in the feedlot

Custo/kg ganho

(Aleitamento + confinamento)

Cost/kg gain (Weaning + feedlot)

(US\$ 0,952)

\section{Conclusões}

O desempenho (ganho de peso e conversão alimentar) dos animais teve influência dos níveis de concentrado, sendo que a ração contendo $90 \%$ de concentrado proporcionou o melhor desempenho no confinamento e os menores valores de custo de produção desses animais.

De maneira geral, todos os animais apresentaram ótimo desenvolvimento em confinamento, para todos os níveis de concentrado estudados, indicando assim a viabilidade de criação desses animais neste sistema.

Por causa do alto custo relacionado à alimentação, novos estudos devem ser realizados referentes à busca de alimentos alternativos, visando diminuir o gasto com este item, sem comprometer o desempenho dos animais e, logicamente, outros níveis de concentrado que sejam viáveis.

Como se trata de um produto que não é muito comum, nas condições de Brasil, seria interessante realizar pesquisas econômicas mais específicas, para se constatar a dimensão do mercado consumidor nacional e sua localização. O mapeamento das bacias leiteiras também seria um ponto importante nesse estudo, com o número de machos que nascem anualmente, assim como a agricultura predominante na região e os subprodutos industriais mais utilizados na alimentação animal, determinando-se, dessa maneira, a forma mais econômica de produção.

\section{Referências Bibliográficas}

ALLEONI, G.F., ABRAMIDES, P.L.G., MATTOS, H.B. 1980 Efeito da suplementação protéica na performance de bovinos machos leiteiros mantidos em pasto consorciados. Bol. Ind. Anim., 37(1):33-45.

BIONDI, P., SCOTT, W.N., FREITAS, E.A.N. et al. 1984 Criação e produção de bovinos machos de raças leiteiras para o corte. Zootecnia, 22(4):281-96.

BOER, T. Veal production in the European Community. New trends in veal calf production. In: INTERNATIONAL SYMPOSIUM ON VEAL PRODUCTION CALF PRODUCTION, 52., 1991, Wageningen-Netherlands. Proceedings... Wageningen: EAAP Publication, 1991.p.8-15.

BOND, J., HOOVEN JR., N.W., WARNICK, E.J. et al. 1972. Influence of breed and plane of nutrition on performance of dairy, dual-purpose and beef steers. II. from 180 days of age to slaughter. J. Anim. Sci., 34(6):1046-1053.

BUHR, B.L. 1996. Hedging Holstein steers in the live cattle futures markets. R. Agric. Econ., 18(1):103-114.

EUCLIDES FILHO, K., FIGUEIREDO, G.R., EUCLIDES, V.P.B. et al. 1996. Conversão alimentar e ganho de peso de animais Nelore e F1's Simental-Nelore e Angus-nelore. In: REUNIÃO ANUAL DA SOCIEDADE BRASILEIRA DE ZOOTECNIA, 33., 1996, Fortaleza. Anais... Fortaleza: SBZ, 1996. p.26. 
FOX, D.G., BLACK, J.R. 1984. A system for predicting body composition and performance of growing cattle. J. Anim. Sci., 58(3):725-739.

GERRITS, W.J.J. 1996. Modeling the growth of preruminant calves. $195 \mathrm{p}$.

GRONEVELT, R. Veal production in North America. New trends in veal calf production. In: INTERNATIONAL SYMPOSIUM ON VEAL PRODUCTION CALF PRODUCTION, 52., 1991, Wageningen-Netherlands. Proceedings... Wageningen: EAAP Publication, 1991. p.16-19.

HIRONAKA, R., FREEZE, B., KOZUB, G.C. et al. 1994. Influence of barley silage:concentrate ratio on rate and efficiency of live weight gain, diet digestibility and carcass characteristics of beef steers. Can. J. Anim. Sci., 74(3):495-501.

LUCCI, C.S. 1989. Bovinos leiteiros jovens. São Paulo: Nobel/ EDUSP. 371p

MERTENS, D.R. Análise da fibra e sua utilização na avaliação e formulação de rações. In: SIMPÓSIO INTERNACIONAL DE RUMINANTES, 1992, Lavras. Anais... Lavras: SBZ, 1992. p.188-219.

NATIONAL RESEARCH COUNCIL - NRC. 1988. Nutrient requirements of dairy cattle. Washington, D.C.: National Academic Press. 90p.

PEREIRA, J.C., OLIVEIRA, R.L. Utilização do bezerro proveniente de rebanhos leiteiros para produção de carne em sistema intensivo. In: SIMBRAS-SIMPÓSIO DE BRASILÂNDIA-SISTEMAS INTEGRADOS DE PRODUÇÃO ANIMAL, 2., Brasilândia de Minas, 2000. Anais... Viçosa: Universidade Federal de Viçosa/ CODEVASF, 2000, p.159-186.

PEREZ REDONDO, F. 1990. Normas de alimentación para el cebo intensivo de terneros frisones. Bovis, 36:37-69.
PRESTON, T.R., WILLIS, M.B. 1974. Intensive beef production. 2.ed. Oxford: Pergamon Press. 546p.

RESENDE, F.D. Efeito do nível de fibra em detergente neutro da ração sobre a ingestão alimentar de bovídeos de diferentes grupos raciais, em regime de confinamento. Viçosa, MG: UFV, 1994. 60p. Dissertação (Mestrado em Zootecnia) Universidade Federal de Viçosa, 1994.

ROHR, K., DAENICKE, R.1984. Nutritional effects on the distribution of live weight as gastrointestinal tract fill and tissue components in growing cattle. J. Anim. Sci., 58(3):753-765.

SILVA, D.J. 1990. Análise de alimentos (Métodos químicos e biológicos). Viçosa, MG: UFV. 160p.

UNITED STATES DEPARTMENT OF AGRICULTURE USDA. 1995. Milk production, dispositions and income, Livestock statistics. Washington, D.C.: U.S. Department of Agriculture.

UNIVERSIDADE FEDERAL DE VIÇOSA - UFV. 1995. SAEG (Sistema de Análises Estatísticas e Genéticas). Viçosa, MG. (Versão 5.0).

Recebido em: 28/08/00

Aceito em: 19/05/01 